\title{
Preferences in regional public transport: a literature review
}

\author{
Joel Hansson ${ }^{1,2^{*}}$ (D) Fredrik Pettersson ${ }^{1,2}$ (D) Helena Svensson ${ }^{1,2}$ (D) and Anders Wretstrand ${ }^{1,2}$ (D)
}

\begin{abstract}
The purpose of this article is to analyse quality attributes of regional public transport and their influence on modal choice, demand, and customer satisfaction through a literature review. The review is based on a working definition of regional public transport with boundaries toward local as well as interregional public transport: Regional public transport (i) targets passengers travelling between separate urban areas or to rural areas and (ii) a majority of the trips are made on a regular basis. Our results suggest that preferences of regional travellers mainly conform to the preferences of local travellers, but some important differences have been revealed. Most notably, on-board comfort is a higher priority for regional travellers and is increasingly important with longer travel times. Network coverage and coordination are also more prominent features of regional public transport, presumably due to the more dispersed nature of regional public transport networks. These differences, and the fact that the prerequisites for regional public transport are in general substantially different compared to local and interregional public transport, support continued use of this categorisation in public transport research. We also conclude that there is a requirement for more knowledge about the specifics of regional public transport, as public transport research, thus far, has been largely focused on local travel. Research areas of particular interest are on-board comfort, operational aspects, travel time improvements, how the environmental impact of public transport services affects modal choice, and the influence of trip length on passenger preferences.
\end{abstract}

Keywords: Public transport, Quality attribute, Service quality, Regional travel, Systematic review

\section{Introduction}

Settlements in rural areas around cities continue to expand across the developed world [1,2]. Commuters living in these areas predominantly use private cars to travel to the cities, adding to congestion, parking and environmental problems and putting the city centre's transport network under continuous strain [3].

Also, for issues regarding greenhouse gas emissions and energy consumption in the transport sector, addressing regional travel is of key importance. In general, short trips are more frequent than longer trips, but the total mileage is dominated by medium and long-distance trips. Moreover, this dominance is likely to increase in the coming decades. According to forecasts produced by the International Transport Forum, non-urban travel demand will grow faster than urban travel demand in

\footnotetext{
* Correspondence: joel.hansson@tft.lth.se

${ }^{1}$ Lund University, Transport and Roads, Box 118, 22100 Lund, Sweden

${ }^{2}$ K2 - The Swedish Knowledge Centre for Public Transport, Bruksgatan 8, 222

36 Lund, Sweden
}

terms of passenger kilometres [4]. In their baseline scenario, $\mathrm{CO}_{2}$ emissions from the non-urban passenger land transport sector is expected to double between 2015 and 2050. To be able to prevent this, incentives for modal shift as well as improved rail and bus services are needed alongside fuel efficiency improvements and increased use of alternative fuels [5].

The recent transport policies and policy-related transport research trends, focusing on replacing (passive) car travel with more active modes like walking, cycling and public transport (e.g. [6]) may suggest that there will be increased need for better regional public transport services. Active living and travel policies target older people [7], children and adolescents [8] as well as the average working population and workplace interventions [9]. Sedentary lifestyles thus affect all generations, and regional public transport services with walking and cycling as first and last mile-solutions, may play an ever so important role in the future. 
For many regional trips, walking and cycling are not viable options, meaning that public transport is often the only alternative to the car for such trips. People in rural areas are at a risk of being excluded from participation in normal relationships and activities if they do not have a driver's licence or access to a car [10]. The quality of regional public transport services impact the independent mobility of this group, particularly children and adolescents [11].

Despite this, public transport research is mainly focused on local travel. In a bibliometric analysis, Heilig \& Voss [12] give insight into the field from a metaperspective. Their keyword analysis indicates that there are few publications that exclusively concern regional public transport, at least compared to research into local public transport. Five of the 59 most used keywords contain urban (urban planning, urban traffic, urban areas, urban development, and urban area). None of the listed keywords relate directly to regional public transport: keywords containing terms such as regional, rural or interurban are absent.

The underrepresentation of regional public transport studies is also acknowledged by de Oña \& de Oña [13] specifically for studies on public transport service quality. While there are numerous publications about service quality analyses in the urban transport sector, as well as for air transport, "the analysis of quality is still found to be waking up in the world of interurban land transport services" ([14], p. 9).

Previous literature reviews have pointed out quality attributes commonly found to be important in local public transport. For customer satisfaction, four quality attributes are of particular importance: frequency, travel time, safety, and punctuality [14]. In addition, costs, staff behaviour, on-board cleanliness and comfort are also commonly discussed as important factors that influence customer satisfaction and loyalty [15]. In terms of attracting car users, though, the factors of importance essentially depend on the context and characteristics of the target group [16]. Modal choice is also considerably affected by factors outside the public transport system, e.g. parking availability in the urban area in question [17].

Public transport mode may also affect the passengers' preferences. For local public transport, rail modes display a more complex pattern of priority areas, compared to bus services, when comparing studies in different settings. For bus services, many studies include similar aspects in the conclusions regarding important quality attributes (see [14]). Bus services are overrepresented in studies into customer satisfaction in local public transport [15], but when comparing the modes, passengers generally prefer rail modes, such as metro and light rail [18]. However, through implementation of high-quality bus concepts such as Bus Rapid Transit, bus services in urban areas can attract as many passengers as light rail and metro, and lead to significant modal shifts similar to those found when implementing rail-based systems [19].

The general characteristics of local travel are different from regional travel (longer distances, often lower service frequencies, fewer stops, etc.), and similarly there are important differences between the regional and interregional levels. These characteristics impact the preferences of potential and existing passengers, e.g. expressed on an urban-interurban scale [20] or a short distance-long distance scale [21].

The aim of this paper is to review research into public transport for regional travel, focusing on important factors for increasing the modal share of public transport in relation to the private car. Because few service quality studies deal explicitly with the effects on modal split, studies concerning demand and customer satisfaction are also included in the review. Customer satisfaction is correlated with demand and modal choice [22], but it is also acknowledged that these are separate concepts, to some extent affected differently by different policies [23]. Furthermore, customer satisfaction is not solely based on the actual conditions of the transport system [24, 25]. The perception of the public transport system is moderated by customer characteristics, situational conditions such as regional or urban setting, and passenger expectations [26]. However, this review includes studies from different contexts in different parts of the world, from suburban rail networks around large cities to bus services in rural settings. We will thereby be able to study patterns beyond the situational conditions, and demonstrate the service attributes that are most commonly found to significantly impact customer satisfaction, demand, and modal choice.

From the review, we will attempt to answer the following research questions:

1. What similarities and differences between regional and local public transport are evident with regards to important quality attributes?

2. Are there any quality attributes whose importance depends on travel time or distance? This question relates to the differences between local and regional public transport but has a broader perspective, aiming to also reveal differences between diverse types of regional travel.

3. Are there any evident differences between bus and rail services in terms of important quality attributes?

4. Do the results of studies into public transport demand and modal choice conform to the results of customer satisfaction studies?

The focus of this review is on conventional bus and rail services (along fixed routes and with fixed schedules) 
serving regional travellers. It is acknowledged that regional public transport has a very diverse service portfolio [3], ranging from demand-responsive services to high-capacity regional rail systems. However, the vast majority of regional passengers use conventional bus and rail services [27].

\section{Definitions}

\subsection{Service quality attributes}

The reviewed studies have different objectives and use different data sources. Consequently, each study assesses different variables. As a framework for structuring the analysis, we have used the categorisation presented in the EU standard EN 13816:2002 [28]. This standard provides an extensive list of service quality attributes, grouped into eight areas:

- Availability. Extent of the service offered in terms of geography, transport modes, operating hours, and frequency.

- Accessibility. Access to the public transport system including interface with other transport systems.

- Information. To assist the planning and execution of journeys, under normal conditions as well as under abnormal conditions such as delays.

- Time. Length of trip time. This area also includes adherence to schedules in the form of punctuality or regularity.

- Customer care. Customer interface, staff behaviour and attitudes, and ticketing options.

- Comfort. Service elements that make journeys relaxing, enjoyable, or productive, e.g. through station facilities, seating and personal space, ride comfort, vehicle condition, atmosphere, and complementary services such as on-board Wi-Fi.

- Safety. Sense of personal protection from crime and accidents.

- Environmental impact. Environmental impact resulting from the provision of the public transport service.

In order to include in the analysis all internal factors over which public transport managers exercise a certain level of control [29], cost has been added to the framework. Cost or fare level is also a commonly discussed policy attribute.

\subsection{Local, regional and interregional public transport}

This paper explores the differences between various geographic scales: local, regional and interregional. However, the boundaries between these geographic scales are unclear and need to be defined in order to conduct the review.
A previous attempt to define regional travel - and hence local and interregional travel - has been made by the UITP [3]. It notes that a single definition is "difficult to establish due to the great diversity that exists within regional transport" (p. 1), and as a result, its definition is somewhat ambiguous. Interestingly, the notion of captive riders is included, possibly indicating the challenge in designing attractive regional public transport services: "Regional public transport covers all collective passenger transport services excluding most public transport within cities and urban centres. In general, regional transport services bring captive riders from lowerdensity and suburban areas to larger city centres and serve small- and medium-sized cities" ([3], p. 1).

A number of other previous publications touch upon definitions of terms related to regional public transport. White [27] adopts the definition of rural transport used in the National Travel Survey in the UK. It concludes that rural areas comprise settlements below 10,000 people or are open countryside. However, White notes that for transport planning purposes, small towns are often also served by rural networks, providing interurban links to larger regional centres of employment, shopping, etc. Village-to-town and town-to-town movements are in many cases served by the same routes.

Exurban is another related term, used by Petersen [30], who writes about public transport for exurban settlements in Australia. He presents two alternative definitions of exurban: "Beyond the suburbs, the Australian exurban region is defined by [ ...] the region surrounding an urban area, bounded on the outer by how far commuters are willing to travel, and on the inner by contiguous urban or suburban development" (pp. 2425). Alternatively, exurban areas can be defined as "the mainly small town and rural regions within 150 kilometres radius from the state's capital and largest city" ([30], p. 25).

A systemisation of bus services in three categories has been made by Godlund [31], as a tool to describe the development of bus services in Sweden from the early years of the twentieth century to the 1950s. The network is categorised into $\alpha$ services, $\beta$ services and $\gamma$ services. The first category, $\alpha$ services, include urban and suburban lines, defined by a maximum distance of $6 \mathrm{~km}$ from an urban area. $\beta$ services include rural to urban services, interurban services with intermediate rural stops, as well as purely rural services. Finally, $\gamma$ services are interurban express lines.

Interurban bus services have been explored in a number of case studies by Luke, Steer \& White [32], describing the current state and future development of such services in the UK. For this purpose, they adopt a working definition of interurban bus: "two or more urban areas (typically towns, but might be cities) are linked by 
a bus service with intermediate stops typically to serve villages en route" (p. 1).

To conclude, existing definitions of regional public transport and related terms such as rural, exurban and interurban are somewhat vague and use various sets of metrics. Besides demographics, the definitions are based on elements such as travel distances or stopping patterns of the public transport services.

In order to sort the terms, we conducted a survey among public transport professionals about their perception of the concept of regional travel (see [33]). The results emphasise the importance of maintaining a distinction between functionality and technology, meaning that factors such as vehicle type or speed should not be included in the definition. Instead, the survey indicates a clear preference for either an administrative or a functional definition, depending on the purpose.

In the administrative version, regional travel is defined by administrative boundaries, i.e. on the outer boundary by county limits, or an agglomeration of counties, and on the inner boundary by city, town or municipality limits. The functional definition is, instead, based on the notions of urban areas and regular travel. Local travel is within an urban area and consequently some portion of a regional trip takes place outside an urban area. For the outer boundary, the functional definition focuses on travel patterns: regional trips are made on a regular basis, daily to weekly in general. This frequency range is based on the survey responses, expressing a need to include also other trip purposes than commuting in the definition of regional travel, such as travel for daily or weekly leisure activities and shopping needs [33].

For practical reasons, trips made on a regular basis can be roughly interpreted as trips within a certain distance or within a certain travel time. However, it is hard to draw a general conclusion about the quantification of such distance or time limits, as they are likely to depend on the national or regional context [33].

For both the (outer) regional-interregional and the (inner) local-regional boundaries, the survey respondents' preferences for the administrative and the functional definitions are roughly equal. One approach could then be to combine these criteria using logical conjunction or disjunction (AND/OR).

In most cases there is a large overlap between the two criteria. As for the regional-interregional boundary, most of the trips made on a regular basis are almost certainly within an administrative unit such as a county or an agglomeration of counties, and vice versa. As for the localregional boundary, most trips to and from an urban area will cross an administrative boundary such as city, town or municipality limits.

To be able to determine how to combine the criteria, we need to examine what lies outside the overlaps. As for the regional-interregional boundary, the administrative definition will include trips that are not made on a regular basis, especially if the administrative region is large. At the other end of the Venn diagram (see Fig. 1), trips made on a regular basis but crossing a regional (or national) administrative boundary, even between towns just a few kilometres apart, are excluded in the strictly administrative definition.

Since this project focuses on passenger preferences and factors that influence ridership on regional public transport services, it is reasonable to exclude longdistance travel within large administrative regions from the definition of regional travel. However, regular travel that crosses administrative boundaries shares key characteristics with other regular travel, and should therefore be included. This means that a combination of administrative and functional criteria is superfluous. The criterion of regular travel is sufficient in itself, for our purpose, and will, moreover, include a majority of the trips that are regional according to the administrative criterion.

The line of reasoning is similar for the local-regional boundary. Trips that cross an administrative boundary but that are carried out within an urban area are local in terms of passenger preferences. At the other end of the Venn diagram (see Fig. 2), trips which, to some extent, pass outside urban areas but are within a local administrative entity have much in common with other interurban or urban-to-rural trips. Analogous to the outer boundary, this means that the functional criterion is sufficient for our purpose and will also in this case include a majority of the trips that are regional according to the administrative criterion.

Thus, for the purpose of exploring passenger preferences, the following working definitions have been adopted in this review:

- Local public transport carries passengers within an urban area. The definition is based on urban areas instead of density or urban centres, implying that travel between different parts of a conurbation (belonging to the same urban area) is local rather than regional.

- Regional public transport targets passengers travelling between separate urban areas or to rural areas, and a majority of the trips are made on a regular basis (daily to weekly, in general). This means that regional travel is not defined as being within a certain geographic area, but is instead based on travel patterns in each case.

- Interregional public transport targets passengers travelling between regions as defined above. Thus, the majority of the trips are made less frequently than weekly. 


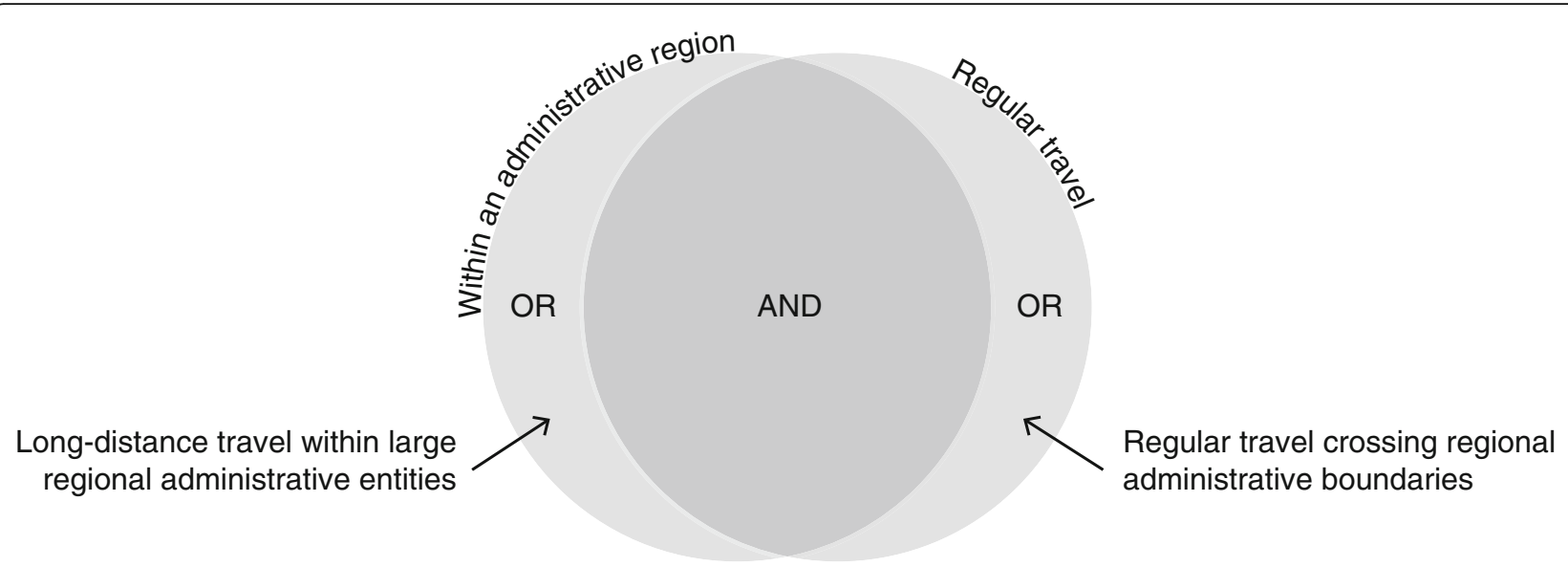

Fig. 1 Venn diagram for the outer boundary of regional travel. Regular travel means that trips are made daily to weekly in general

The definitions focus on travel patterns rather than individual trips. On a regional public transport service, the majority of passengers travel between separate urban areas or to rural areas, and the majority of these trips are made on a regular basis. This implies that most passengers on regional services are frequent travellers, but not necessarily all of them.

\section{Method}

This study uses the PRISMA method [34] to identify and systematically analyse relevant literature on important service quality attributes in regional public transport. The PRISMA method is chosen due to its structured, iterative process for identifying a comprehensive set of studies that meet the specified aim of this study [34].

The process includes three phases (Fig. 3): First, a set of literature is gathered through an extensive search in Scopus and TRID - Transport Research International Documentation. In the second phase, the identified literature is assessed using a set of inclusion and exclusion criteria. Titles, abstracts, and full-text articles, respectively, are assessed, narrowing down the literature list in each step. Before the full-text assessment, literature found via citation searches is added to complement the literature identified in the database searches. The third and final phase of the process is a qualitative synthesis of the selected literature.

In order to identify relevant search terms, the research subject was broken down into three main concepts: ridership, regional, and public transport. For each of these concepts, synonyms, broader terms, narrower terms, and related terms were identified through a combination of citation searches and using the Transportation Research Thesaurus [35]. The resulting search terms, listed in Table 1, were combined using building block searches. In addition, the searches were limited to literature written in English and published before July 2018 when the search was conducted.

The titles, abstracts, and finally the full-text literature have been assessed using a number of inclusion and exclusion criteria. Besides the language and publication date limitations mentioned above, we have used three

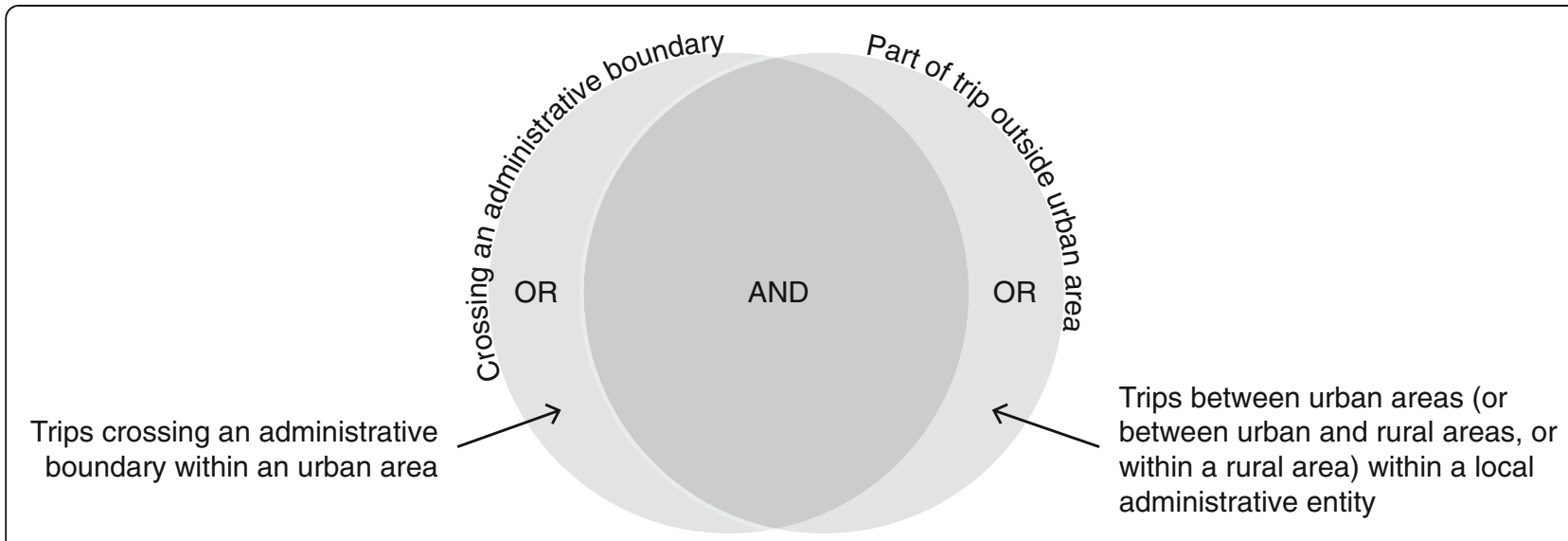

Fig. 2 Venn diagram for the inner boundary of regional travel 


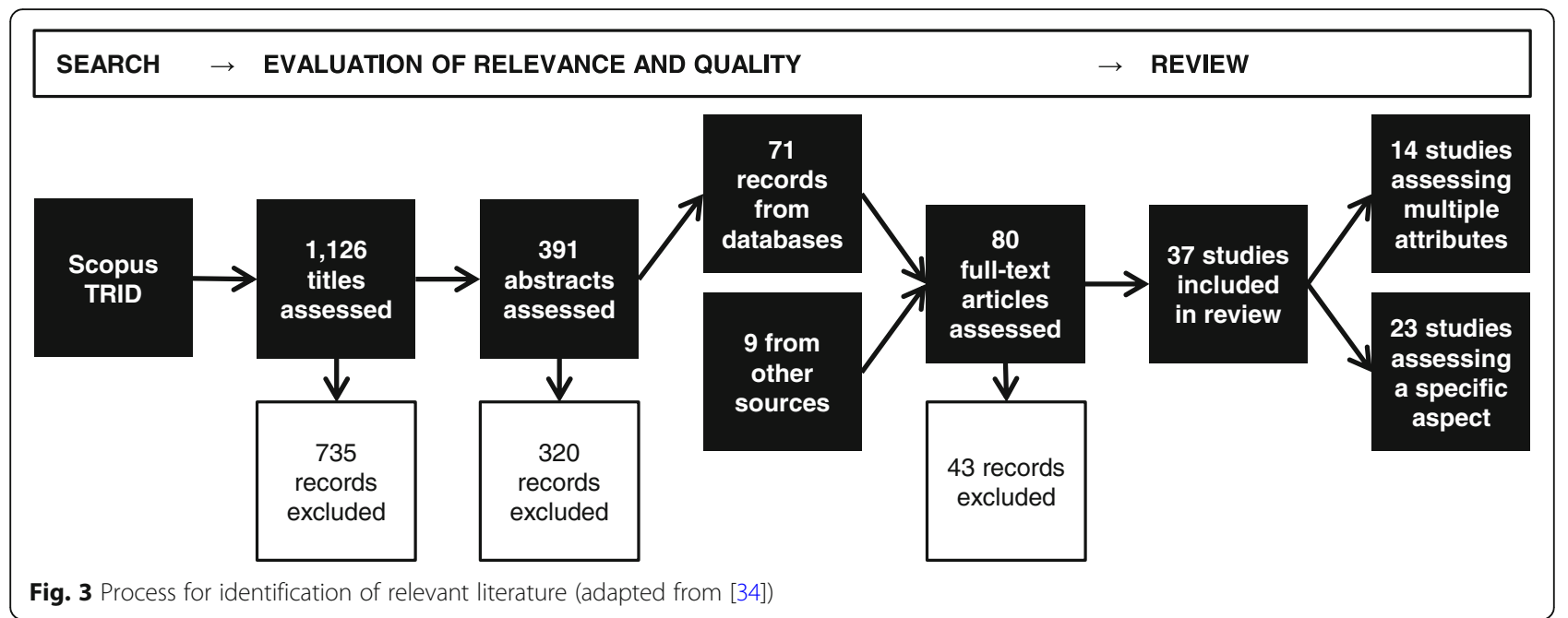

relevance criteria to narrow down the results. Firstly, the study case must be in line with our definition of regional public transport. In studies covering more than just regional public transport, for example, both local and regional public transport in a metropolitan area, results regarding regional travel have to be explicitly reported. Secondly, the study must cover one or multiple service quality attributes and their influence on modal split, ridership, or customer satisfaction. Thirdly, we only include studies about conventional modes of regional public transport, i.e. train and bus services along fixed routes and with fixed timetables. Paratransit and demand-responsive services, as well as air services, have been excluded.

\section{Results}

Thirty-seven studies were selected for review (references $[20,24,36-70])$. The selection is centred upon recent publications: 31 of the studies have been published during the last 10 years and 23 of them as recently as during the last five-year period. This pattern was also evident in the initial search results, indicating an increasing trend for research into service quality in regional public transport.

Studies from different geographic contexts are included in the review, from the suburbs and rural areas around Mumbai [36-38] and Shanghai [39] to smalltown regions in Texas [40] and southern Italy [24]. These differences in city and region size mean different realities in the public transport systems. For instance, crowding is a common issue around large cities (see [38, 41]), while other types of comfort-related attributes are more important in less densely populated areas (see [20, $40,42,43])$. Geographic context is indicated in the review when relevant.

Fourteen of the selected studies comprise evaluations of multiple quality attributes, enabling suggestions about the relative importance of these attributes. These studies are outlined in section The relative importance of quality attributes, providing an overview of important quality attributes in regional public transport. The focus of this section lies on a quantitative assessment of these 14 studies. The remainder of the studies that were identified in the search process are focused on specific attributes, providing more in-depth information about

Table 1 Search terms, based on the three concepts ridership, regional, and public transport

\begin{tabular}{|c|c|c|c|c|}
\hline Ridership & & Regional & & Public transport \\
\hline $\begin{array}{l}\text { ridership OR } \\
\text { patronage OR } \\
\text { demand OR } \\
\text { quality OR } \\
\text { attitude OR } \\
\text { perception OR } \\
\text { satisfaction OR } \\
\text { improvement OR } \\
\text { upgrade }\end{array}$ & AND ( & $\begin{array}{l}\text { regional OR } \\
\text { rural OR } \\
\text { semirural OR } \\
\text { "semi-rural" OR } \\
\text { exurban OR } \\
\text { "ex-urban" OR } \\
\text { periurban OR } \\
\text { "peri-urban" OR } \\
\text { suburban OR } \\
\text { interurban OR } \\
\text { "inter-urban" }\end{array}$ & PRE/0 & $\begin{array}{l}\text { "public transport*" OR } \\
\text { transit OR } \\
\text { bus OR } \\
\text { coach OR } \\
\text { rail* OR } \\
\text { passenger }\end{array}$ \\
\hline
\end{tabular}

In Scopus, the concepts regional and public transport were combined with the operator PRE/0, meaning that the terms must be adjacent. TRID, however, lacks this functionality. Thus, all three concepts were combined with the AND operator. The asterisks are multi-character wildcards, enabling inclusion of various suffixes of the chosen keywords. For example, the search term "public transport*" includes studies using one of the terms "public transport" or "public transportation" 
various aspects of regional public transport networks. Results from a qualitative assessment of these studies, and of the 14 "overview studies", can be found in sections Cost to Comfort. The structure of this part of the review reflects the content of the selected studies, sorted into some of the categories used in section The relative importance of quality attributes. In section Research gaps we return to the full framework of attribute categories (see section Service quality attributes) in order to identify gaps in the literature.

\subsection{The relative importance of quality attributes}

Results from the 14 studies comprising evaluations of multiple quality attributes are summarised in Table 2 . In the table the results are visualised through quality attribute categories (see section Service quality attributes) that are discussed by the authors as being important or found to have major impacts in the analyses. In most cases, each category included comprises several more specific quality attributes. For instance, the category "Availability" may for a specific study include attributes concerning frequency as well as attributes about network coverage. To be able to separate these attributes, a more fine-grained analysis have been carried out. For reasons of clarity, however, the results are presented on category level in Table 2. It should also be noted that the notions for similar quality attributes vary between the studies, and in those cases we have made interpretations according to the framework described in section Service quality attributes.

For each publication, public transport modes included in the study are specified, as well as the output variable: modal choice, demand, or customer satisfaction. We have also made rough estimations of average travel distances in the samples, as they are usually not explicitly reported in the studies, and assigned each study to one of the three distance categories: short (less than $25 \mathrm{~km}, 6$ studies), medium ( $25-50 \mathrm{~km}, 3$ studies), and long (more than $50 \mathrm{~km}, 4$ studies). The three distance categories have been chosen based on the availability of results from the investigated studies. One of the studies covers multiple geographical scales. Thus, it has not been assigned to a distance category.

In addition, the type of data used in each study is also specified in Table 2. The most commonly used data sources in the selection of studies comprise different types of stated preference surveys and customer satisfaction surveys, often in combination. It should be noted that the notion of stated preference is used here as a wide concept, ranging from directly stated importance of different attributes to discrete choice experiments. Revealed preference data is only used in three of the studies, through ridership data or a survey.
Cost, availability, time, and comfort are the most commonly explored categories, covered in almost all of the selected studies. Most of the other categories are also quite well represented, as they are included in at least half of the studies. The exception is environmental impact, which is included in only two of the studies.

Three of the categories are mentioned in the discussion of the most important variables in most of the studies in which they have been included:

- Availability, whereof frequency of service appears to be of particular importance. Frequency is the most common individual attribute in the discussions about important attributes. Another availability attribute commonly discussed is network coverage (and walking distance).

- Time, whereof reliability and punctuality are the most common attributes mentioned in the discussions. Travel time also appears in the discussion about important attributes in more than half of the studies in which it has been included.

- Comfort, which is typically represented by different attributes related to on-board comfort, such as crowding, cleanliness, ventilation, vehicle condition, etc. A number of studies also find station facilities to be of importance.

A couple of the studies include comparisons of local and regional travel. Majumdar \& Lentz [40] suggest that the results in rural areas do not differ very much from the results in urban areas. In contrast, Stern [51] concludes that the urban and rural population ascribes different preferences to service attributes. Román, Martín, \& Espino [20] find that interurban passengers place more emphasis on comfort, and less on frequency, than urban passengers. In fact, comfort is found to be the most important attribute for interurban passengers, and frequency is a top priority for urban passengers.

A similar pattern is evident in the comparison between short, medium, and long regional trips in Table 2. All studies of medium and long regional trips include some aspect of on-board comfort in the discussion of important attributes. However, in the studies of short regional trips these attributes are absent in the discussion (a couple of these studies instead find station facilities important, which is another aspect of the comfort category). Additional support for this finding is expressed by Bouscasse, Joly, \& Peyhardi [36] through a positive crossed effect between travel time and comfort, which means that the value of comfort increases as travel time increases.

In addition, the results indicate that cost is a more important attribute for medium and long regional trips than for short regional trips. 


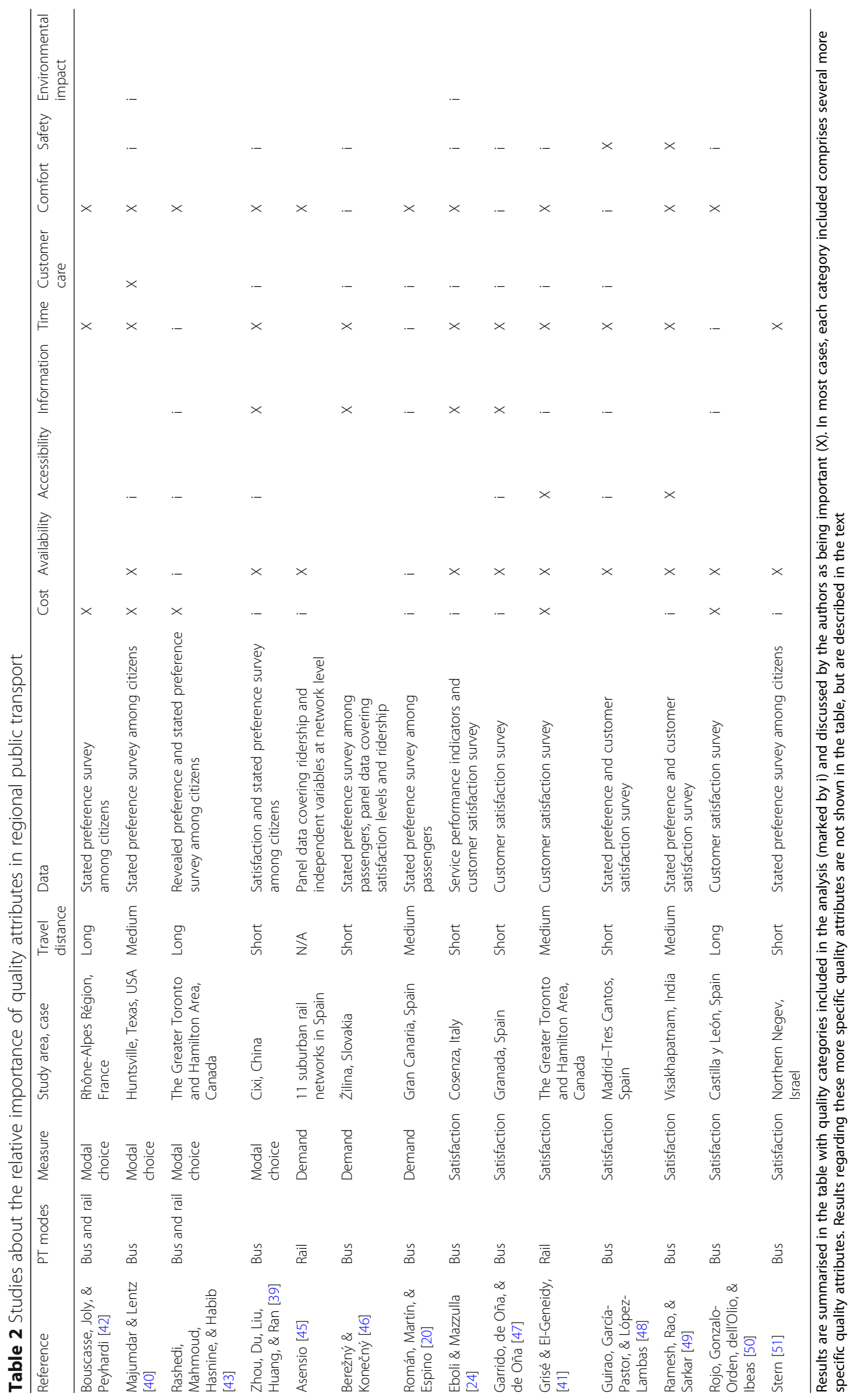


The opposite could be said for information, which is found to be important in all but one of the studies of short regional trips (where included), but in none of the studies of medium and long regional trips. A similar tendency is also found for frequency and reliability, although not as pronounced.

In terms of differences between bus and rail services regarding the relative importance of quality attributes, no conclusions can be drawn from the studies in Table 2 due to the low number of such studies that focus entirely on rail services.

The results of studies into modal choice and demand largely conform to the results of the customer satisfaction studies. A couple of differences can be discerned: more emphasis is placed on frequency and reliability in the customer satisfaction studies. However, these differences are not convincingly transparent and there is also an overrepresentation of customer satisfaction studies regarding short regional trips and bus users. Hence, it is hard to determine whether the differences relate to the type of study, travel distances, public transport mode, or to all of those.

\subsection{Cost}

Firstly, it is important to note that cost cannot be seen as an isolated entity, it is rather the relationship between quality and price that affects users the most [50].

In terms of price elasticity, the demand for regional public transport services is inelastic, i.e. typically between -1 and $0[37,45,52]$, and the demand adjusts very quickly after any change in fare levels [37]. Price elasticity differences between bus and rail services are found to be minimal $[36,52]$ and no significant difference has been detected between elasticities of demand for day and season tickets [52]. Furthermore, Stark [52] found that price elasticities may vary with distance - absolute elasticity values fell with increasing distance up to around $20 \mathrm{~km}$ and then rose again. However, it should be noted that the number of cases in this study was too low for a more general conclusion to be justified.

Integrated local-regional fare systems are crucial in order for users to access a coherent public transport network at a reasonable cost. Rashedi, Mahmoud, Hasnine, \& Habib [43] revealed that eliminating additional costs for regional transit users when using local transit for access or egress is an effective strategy for improving the modal share of public transport for regional commuting trips.

\subsection{Availability and accessibility 4.3.1 Planning and organising regional public transport networks}

The coordination of public transport systems, not only through integrated fares but also through integrated ticketing and coordinated transport planning, marketing, and customer information, is a foundation for providing an attractive alternative to the car. Buehler, Pucher, \& Dümmler [53] suggest that such coordination, in the form of so-called Verkehrsverbund, is a part of the explanation of why the modal share of private cars has fallen since 1990 in many German, Austrian, and Swiss metropolitan areas. In all six of their case studies, they argue that the integrated public transport associations have increased the quality and quantity of services, attracted more passengers, and reduced the proportion of costs covered by subsidies.

Coordination is also a key element for making public transport attractive and cost-effective outside the most densely-populated areas. Despite low frequencies, it is possible to create an attractive public transport network through rigorous coordination and central network planning [54]. Integrated timed-transfer systems with pulse timetables can operate with more than adequate levels of cost recovery and vehicle occupancy even in rural regions with very low population densities [55]. Demandresponsive services may enable larger areas to be covered, to meet planning objectives of ensuring a minimum of level of service. However, conventional interurban services between towns can provide a more cost-effective way of serving rural areas in which smaller settlements are concentrated along corridors $[55,56]$.

\subsubsection{Regional public transport modes: bus versus rail}

The coordination of public transport networks also includes the coordination of modes. Brown \& Thompson [57] argue that the combination of a rail service backbone and a multi-destination service strategy - feeder services to rail stations rather than parallel direct services - is a prosperous approach. Easy and well-timed transfers are fundamental to making this strategy successful $[54,55,57]$.

A couple of studies indicate that trains are preferred to buses in general, or that bus or coach services are considered to complement rail services [58, 59]. There are exceptions in which coaches can achieve comparable trip times to rail [59] though the perception of the modes is not only based on performance and cost criteria. There are also other more subjective criteria related to travel emotions or sensory aspects that might explain the differences in perception [58].

Bazley, Vink, \& Blankenship [60] describe the concept of "Rural Bus Rapid Transit" as an alternative to rail in rural settings. Such a concept was inaugurated in 2013 between Aspen and Glenwood Springs, USA, covering a distance of approximately $70 \mathrm{~km}$ with 13 bus stations. The concept comprises high standards of operations as well as vehicles and station facilities. A few months after introduction, ridership had increased by $22 \%$ and, 
according to a customer satisfaction survey, this is mainly due to station locations, frequency, bus comfort and safety.

\subsubsection{Access and egress}

Integration of local and regional public transport networks is described above as an important factor for the availability of the system. In the design of the system, this needs to be balanced with other modes of access and egress to regional public transport stations. For instance, Akbari, Mahmoud, Shalaby, \& Habib [61] suggest that the number of bus stops should be limited within the walking catchment area of a station, for the benefit of walking access. They define the walking catchment area as an $800-\mathrm{m}$ radius around the station.

Four hundred or eight hundred meters, roughly a 5or 10-min walk, are conventionally assumed distances for walking catchment areas, but there are studies which demonstrate that many passengers are willing to walk substantially further. For instance, data from regional buses around Amsterdam show that the 90-percentile of the walking access distance is somewhere in the range of 1,200-1,500 m [62]. Walking distances to suburban rail stations in Perth, Australia, are even longer, with significant numbers of passengers walking as far as $2-3 \mathrm{~km}$ to the stations [63]. However, it should be noted that characteristics of the built environment significantly affect trip production by walk access [61].

Higher speed and frequency of public transport services increase the catchment area, although this effect is not as apparent for walking as it is for cycling. The 90percentile of the catchment radius for high-quality bus services around Amsterdam ("R-Net") is almost double the catchment radius for conventional services ("Comfortnet"), 3,000 $\mathrm{m}$ vs $1,500 \mathrm{~m}$. For walking access, the differences are not as evident. Also, the bicycle is a more important access mode for the high-quality system than for conventional bus services. The mode share of the bicycle is significantly higher for access to "R-Net" than for access to "Comfortnet" [62].

For car access there are also indications of a positive relationship between quality of service and catchment area. Higher frequencies mean that people are willing to drive longer distances [64]. Additionally, driving distances to stations are affected by overall trip lengths, i.e. longer public transport trips mean longer average driving distances to stations [64].

In general, the importance of car parking at stations, or park-and-ride facilities, increases with distance from the destination [65, 66]. Accessible and inexpensive car parking at stations can encourage motorists to shift to public transport modes for part of their trip [65] and make daily travel easier for many commuters. However, offering passengers free parking at stations also has negative consequences and, in most cases, free parkand-ride cannot be assumed as a measure of reducing traffic volumes or greenhouse gas emissions from traffic [66]. Traffic volumes may even increase if a park-andride facility occupies a site which has an alternative use that could contribute to less transport demand and traffic, or if the park-and-ride facility means car journeys replace walking, cycling or using public transport to access the station [66].

Monetising parking at stations will stop some regional travellers from using public transport. Nevertheless, it is a way of managing parking demand and improving access times for park-and-ride users [43]. Reasonable daily parking charges (compared to the cost of driving to considerably more expensive parking facilities at the destination) can also provide sufficient capital to build and operate new park-and-ride capacity without subsidies from other revenue sources [67].

\subsection{Time \\ 4.4.1 Reliability}

In many of the reviewed studies reliability is equalled with punctuality, even though reliability often is understood as a wider concept. The EU standard EN 13816: 2002 [28] (see section Service quality attributes) separates punctuality - on-time performance - from regularity - maintaining headways - but this differentiation is absent in the reviewed studies. However, there are some cases where the concept of reliability is diversified in other ways. Reliability of connections is sometimes separated from general punctuality, and it is shown that reducing the probability of delays is particularly important for passengers with transfers $[46,59]$. Another aspect is the occurrence of cancelled runs, which self-evidently may come out as an important facet of reliability in studies where it is separated from on-time performance [24]. In a broader sense, reliability can also be affiliated with concepts such as permanence and simplicity, implying a general preference for carefully planned, fixed public transport routes combined in a stable network [55].

Still, punctuality is the most common measure of reliability, and it is shown that delays significantly impact the level of passenger satisfaction [68]. Higher probability of delays also decreases the probability of choosing public transport modes $[39,43]$. The importance of the issue increases with low frequencies [59]. Also, evidence from the suburban railway network in Paris suggests that passengers travelling for other purposes than commuting value punctuality even more than commuters [69]. A related issue is communicating information about service disruptions, which is highly valued among all passengers $[41,69]$. Specifically, explicit information about the expected duration of delays is particularly appreciated [69]. 


\subsection{Comfort}

The notion of comfort covers a wide range of quality attributes, for example, station facilities, crowding, noise, ride comfort, etc. In general, on-board facilities have a higher impact on perceived service quality in regional public transport than station facilities [68]. Complementary services such as on-board Wi-Fi may also significantly impact modal choice in favour of public transport [70].

Depending on passenger flows, crowding is an important factor to take into account when designing regional public transport services. In rural areas, passenger flows are generally relatively low. Thus, frequencies are largely determined by other aspects, i.e. balancing operational costs and waiting times [43]. In more densely populated areas, however, crowding is a critical factor. As the level of crowding increases, the total perceived in-vehicle travel time increases [38]. Females tend to perceive a higher reduction in utility due to crowding than males. Similar preferences are observed for higher income groups [38]. However, the effects of crowding are not inherently or unavoidably negative. A crowd can be a source of entertainment, fun, and friendship [36]. Thus, it is important to understand the specifics of the crowd, such as the density, passenger perceptions and culture.

\subsection{Research gaps}

Returning to the framework of quality attribute categories (see section Service quality attributes), cost, availability, time, and comfort are the most commonly explored categories, covered by more than half of the reviewed studies (Table 3).

Availability is the most widely covered category, with a focus on modes (bus vs rail) and network (coordination, transfers, access and egress). However, elaborations of the operational aspect of availability, i.e. operating hours and frequency, are missing.

Regarding the time category, the reviewed studies focus on reliability. Elaborations of travel time, for example, studies about travel time improvements in regional public transport, are absent.

The reviewed studies on comfort are mainly centred on crowding. As mentioned above (section Comfort), there are many further aspects of comfort that are yet to be investigated.

Attributes regarding accessibility, information, customer care, security, and environmental impact are touched upon in some publications, but without any further elaboration. The least explored category, environmental impact, and its effect on modal choice, ridership or customer satisfaction, is mentioned in only three of the 37 publications.

\section{Discussion}

The objectives of this review were framed in four research questions, discussed in the following sections, together with some suggestions for future research. Many of the results from this review are indicative rather than conclusive, due to the little amount of previous research in the topic. The fact that the reviewed studies differ in methods used and factors controlled for also limits the possibility for solid conclusions. Still, the review provides an overview of quality studies conducted in regional public transport and demonstrates some quality attributes that are recurringly found to be important in these studies.

It should be noted that there is a variation in the reviewed studies regarding how quality attributes are defined and used. This complicates the assessment, but through transformation to the framework presented in section Service quality attributes we have been able to compare studies and reveal some overall patterns. The discussion and conclusions are based on this framework, but the original studies might use different notations.

\subsection{Comparison of regional and local public transport}

This review has shown that frequency, comfort, reliability, travel time, and network coverage are particularly important quality attributes in many studies into regional public transport. Comparing this result with similar reviews about local public transport [14, 15], the general impression is that the preferences of regional travellers mainly conform to the preferences of local travellers. This is also suggested by Majumdar \& Lentz [40]. However, our review also highlights some important differences.

Frequency is among the highest ranked attributes in both local and regional public transport, though the results also indicate that the importance of frequency is less pronounced among regional travellers. Instead, in this group, comfort is a higher priority [20].

Attributes concerning network coverage or walking distance are seemingly more frequent in discussions about important attributes in regional public transport than in local public transport. A probable explanation is the more dispersed nature of regional public transport networks, together with the challenge of designing coherent networks in which frequencies are typically low. A proven remedy, however, is easy and well-timed transfers, achieved through rigorous coordination and central network planning [54, 55, 57]. In addition, the conditions for access and egress to and from stops and stations need attention, including beyond the conventionally assumed catchment areas of 400 or $800 \mathrm{~m}$. Many passengers are willing to walk substantially further if the appropriate infrastructure exists $[62,63]$, even if these results depend on sociodemographic characteristics (such as age) and characteristics of the built environment (such as walkability). Cycling also has the potential to be an important access mode, especially for high-quality regional services, increasing the 
catchment area to several kilometres [62]. Moreover, park-and-ride facilities can improve access to the public transport network in cases where overall trip lengths are relatively long $[65,66]$.

In contrast to comfort and network coverage, attributes concerning security and staff do not appear to be as highly prioritised in regional public transport as in local public transport.

The notions of local and regional public transport are rarely used in the literature. Urban, rural, and interurban are more common concepts and substantial parts of the review are based on studies using these notions. As regional is not synonymous with rural or interurban, all parallels need to be handled with care. However, with the definition of regional public transport that we have adopted in this review, which is based on urban areas rather than administrative boundaries, studies of rural and interurban travel, in most cases, will fall within our definition of regional. This is illustrated in the Venn diagram in Fig. 2, in which the right-hand circle corresponds to our working definition. Furthermore, we have assessed each case study to confirm that it is in line with our definition.

\subsection{The influence of trip length}

Our results indicate that there are quality attributes whose importance depends on trip length. Based on the availability of results from the investigated studies, three distance categories have been defined - short (less than $25 \mathrm{~km}$ ), medium $(25-50 \mathrm{~km}$ ), and long (more than 50 $\mathrm{km}$ ). Passenger preferences appear to differ between short regional trips compared to medium and long regional trips. Unsurprisingly, the results reveal that these differences are essentially in line with the differences found between local and regional travel.

The most pronounced differences appear in attributes regarding on-board comfort, the importance of which quite logically appears to increase with travel distance.
Comfort in terms of station facilities is reported to have less impact on perceived service quality in regional public transport [68], although the results of our review suggest that this conclusion might require modification. On-board comfort is clearly important for medium and long regional trips, but there are indications that station facilities are more important for short regional trips.

Also in line with local-regional differences, the importance of frequency and reliability appear to decrease somewhat with travel distance. A possible explanation for this is that as travel distance increases, in-vehicle travel time increases, meaning that waiting time and potential delays constitute relatively smaller portions of the total travel time. It should be noted, however, that frequency and reliability still are among the top priorities also for long regional trips.

More surprisingly, price appears to be less important for short regional trips than for local trips and for medium and long regional trips. This finding is principally based on patterns appearing when comparing results from studies carried out in different settings regarding travel distances. Only one of the studies uses a comparative method, observing a decrease in price elasticity up to around $20 \mathrm{~km}$, from where it starts increasing again [52]. This result is in line with the overall pattern, but it should be noted that it is based on relatively few observations.

As there are many similarities between the local-regional comparison and the short-long trip comparison, a relevant question is whether the segmentation between local, regional, and interregional is necessary. Is segmentation based on trip lengths, or travel times, more suitable? Indeed, the relative importance of different quality attributes probably depends more on travel times and trip lengths than on the urban or regional context. However, the prerequisites for regional public transport are generally significantly different compared to local public

Table 3 Inclusion of quality attribute categories in the reviewed studies

\begin{tabular}{llll}
\hline Category & \multicolumn{2}{l}{ Number of studies in which a quality attribute in the category is included } \\
\cline { 2 - 4 } & $\begin{array}{l}\text { "Overviews" } \\
(N=14)\end{array}$ & $\begin{array}{l}\text { "Specialisations" } \\
(N=23)\end{array}$ & $\begin{array}{l}\text { Total } \\
(N=37)\end{array}$ \\
\hline Cost & 12 & 7 & 19 \\
Availability & 12 & 17 & 29 \\
Accessibility & 7 & 8 & 15 \\
Information & 9 & 4 & 13 \\
Time & 13 & 8 & 21 \\
Customer care & 8 & 2 & 10 \\
Comfort & 13 & 6 & 19 \\
Security & 9 & 2 & 11 \\
Environmental impact & 2 & 1 & 3
\end{tabular}

"Overviews" correspond to the studies included in Table 2, and "specialisations" comprise the remainder of the studies that were identified in the search process and included in the review 
transport, so the separation of geographical scales is still relevant. We suggest using a combination where possible, separating short from long trip lengths, or travel times, within each category (e.g. short local trips, long local trips, short regional trips, long regional trips). A similar approach is also reasonable for interregional public transport, separating it from regional public transport based on trip regularity (in line with our working definition, see section Local, regional and interregional public transport) and, where possible, also keeping track of the influence of trip length or travel time.

\subsection{Bus versus rail}

We have not been able to find any differences between bus and rail services in terms of how quality attributes are prioritised. Comparisons are aggravated by the fact that passenger satisfaction levels are moderated by their expectations [26] and expectations differ between the modes based on subjective criteria related to travel emotions or sensory aspects [58]. Nevertheless, there are indications of a general preference for trains over buses $[58,59]$. Thus, the development and evaluation of rail-inspired bus concepts such as "Rural Bus Rapid Transit" [60] or "R-Net" [62] could be an interesting and potentially prosperous way forward for regional bus and coach services.

Compared to local public transport (outlined in the introduction), there are similarities in terms of how bus services are overrepresented in studies into customer satisfaction. Also, rail is generally favoured compared to buses in both local and regional public transport. For local public transport, this gap in perception can be bridged through high-quality bus services such as Bus Rapid Transit, which has been implemented in many cities and now becoming a well-established concept the world over [19]. Efforts for developing similar high-quality bus concepts on a regional scale are, however, rare.

\subsection{Modal choice, demand, and customer satisfaction}

As outlined in the introduction, customer satisfaction, demand, and modal choice are intertwined concepts, each impacting the other. In this review, we have been unable to find any substantial differences, in terms of important quality attributes, in the conclusions of customer satisfaction studies compared to studies on demand or modal choice. A couple of minor dissimilarities were indicated in the results, but it is difficult to draw robust conclusions in this regard. This is due to a risk of spuriousness between type of study and other factors such as trip length and public transport mode.

Analogous to studies into local public transport, customer satisfaction studies predominantly focus on bus services. A possible explanation is that bus generally is the least favoured mode, yet constituting significant parts of the public transport networks in many cities and regions, implying that many transport authorities would benefit from increasing customer satisfaction among bus users [15].

\subsection{Directions for future research}

As outlined in the introduction, public transport research has largely been focused on local travel and there are relatively few publications that exclusively concern regional public transport [12-14]. There is a need for more knowledge about the specifics of regional public transport and, based on our results regarding important quality attributes, combined with identified gaps, we can offer some suggestions about the direction of future research:

- On-board comfort is a top priority for many regional travellers, but this is a multifaceted attribute and more research is needed into the impact of different aspects of on-board comfort, e.g. seating, ride comfort, and complementary facilities.

- Frequency is also acknowledged to be an attribute of great importance, but the reviewed studies have not revealed many details of operational aspects such as peak and off-peak frequencies or operating hours.

- Surprisingly little attention has been paid to travel time improvements, regarding in-vehicle travel time in particular, given that in-vehicle travel time generally constitutes a relatively large proportion of the total travel time in regional public transport.

- Little is known about how the environmental impact of public transport services affects modal choice for regional travel, as this attribute is rarely included in such studies.

- Our review suggests that trip lengths or travel times affect passenger preferences, but the mechanisms are still largely unclear. Further studies that include the crossed effects between trip length or travel time and other service attributes are desirable.

\section{Conclusions}

For the purpose of exploring passenger preferences, the following working definition of regional public transport can be adopted, with boundaries towards local as well as interregional public transport. Regional public transport (i) targets passengers travelling between separate urban areas or to rural areas and (ii) a majority of the trips are made on a regular basis. The second part of the definition implies that most passengers on regional public transport services are frequent travellers, and hence, our results mainly target frequent travellers.

Quality attributes commonly reported as priorities for regional travellers are frequency, comfort, reliability, travel time, and network coverage. Some important differences with regard to local public transport are suggested. Firstly, on-board comfort is a higher priority for 
regional travellers, becoming increasingly important with longer travel times. Secondly, network coverage and coordination are also more prominent features in regional public transport, presumably because of the more dispersed nature of regional public transport networks. In relation to this, it has been concluded that catchment areas for walking and cycling to high-quality regional public transport services can be substantially larger than the conventionally assumed 400 or 800 m radius.

These differences, and the fact that the prerequisites for regional public transport are, in general, substantially different compared to local and interregional public transport, support continued use of this categorisation in public transport research. Where applicable, we also suggest inclusion of the impact of trip length or travel time within each category.

Trains are generally found to be preferred to buses and we therefore suggest further development and evaluation of rail-inspired bus concepts. However, we have not found any differences between bus and rail services regarding quality attribute priorities.

Our review does not indicate any substantial differences in terms of important quality attributes in the conclusions of customer satisfaction studies compared to studies into demand or modal choice.

\section{Acknowledgements}

The authors would like to thank all respondents for their valuable input in the survey. Thanks also to the staff at the LTH library services for their constructive advice.

\section{Authors' contributions}

$\mathrm{JH}$ conducted the survey, the literature search and assessments, and did most of the writing. FP assisted with the literature assessments and made intellectual contributions to the analyses. HS made intellectual contributions to the analyses. AW assisted in developing the framework and made intellectual contributions to the analyses. All authors read and approved the final manuscript and agree with its submission to European Transport Research Review.

\section{Funding}

This study was funded by the Swedish Transport Administration through K2 - The Swedish Knowledge Centre for Public Transport.

\section{Availability of data and materials}

The datasets used and analysed during the current study are available from the corresponding author on reasonable request.

\section{Competing interests}

The authors declare that they have no competing interests. We confirm that this manuscript has not been published elsewhere and is not under consideration by another journal. Section Local, regional and interregional public transport in the manuscript is a summary of a previously published working paper (cited in the manuscript and available on-line).

Received: 14 February 2019 Accepted: 3 July 2019

Published online: 22 July 2019

\section{References}

1. EEA, European Environment Agency. (2016). Urban Sprawl in Europe (EEA Report No 11/2016). https://doi.org/10.2800/143470.
2. WHO \& UN, World Health Organization \& United Nations. (2010). Hidden cities: Unmasking and overcoming health inequities in urban settings. Geneva: WHO Retrieved from https://apps.who.int/iris/handle/10665/44439.

3. UITP, International Association of Public Transport. (2013). Demographic changes and challenges for regional transport (Core brief). Brussels: Author.

4. ITF, International Transport Forum. (2017). ITF transport outlook 2017. Paris: OECD Publishing. https://doi.org/10.1787/9789282108000-en.

5. Chen, G., \& Benezech, V. (2018). Non-urban passenger travel demand and $\mathrm{CO}_{2}$ emissions: A global perspective. Transportation Research Board 97th Annual Meeting. https://trid.trb.org/view/1496014.

6. Petrunoff, N., Rissel, C., \& Wen, L. M. (2016). The effect of active travel interventions conducted in work settings on driving to work: A systematic review. Journal of Transport \& Health, 3(1), 61-76. https://doi.org/10.1016/j. jth.2015.12.001.

7. Aguiar, B., \& Macário, R. (2017). The need for an elderly centred mobility policy. Transportation Research Procedia, 25, 4355-4369. https://doi.org/10.1 016/j.trpro.2017.05.309.

8. Mehdizadeh, M., Mamdoohi, A., \& Nordfjaern, T. (2017). Walking time to school, children's active school travel and their related factors. Journal of Transport \& Health, 6, 313-326. https://doi.org/10.1016/j.jth.2017.01.012.

9. Commissaris, D. A., Huysmans, M. A., Mathiassen, S., Srinivasan, D., Koppes, L. L., \& Hendriksen, I. J. (2016). Interventions to reduce sedentary behavior and increase physical activity during productive work: A systematic review. Scandinavian Journal of Work, Environment \& Health, 42(3), 181-191. https:// doi.org/10.5271/sjweh.3544.

10. Lucas, K. (2012). Transport and social exclusion: Where are we now? Transport Policy, 20, 105-113. https://doi.org/10.1016/.tranpol.2012.01.013.

11. Berg, J., \& Ihlström, J. (2019). The importance of public transport for mobility and everyday activities among rural residents. Social Sciences, 8(2), 58. https://doi.org/10.3390/socsci8020058.

12. Heilig, L., \& Voss, S. (2015). A Scientometric analysis of public transport research. Journal of Public Transportation, 18(2), 111-141. https://doi.org/10.5 038/2375-0901.18.2.8.

13. de Oña, J., \& de Oña, R. (2015). Quality of service in public transport based on customer satisfaction surveys: A review and assessment of methodological approaches. Transportation Science, 49(3), 605-622. https:// doi.org/10.1287/trsc.2014.0544.

14. dell'Olio, L., Ibeas, A., de Oña, J., \& de Oña, R. (2018). Public transport quality of service. Amsterdam: Elsevier.

15. van Lierop, D., Badami, M. G., \& El-Geneidy, A. M. (2018). What influences satisfaction and loyalty in public transport? A review of the literature. Transport Reviews, 38(1), 52-72. https://doi.org/10.1080/01441647.2017.1298683.

16. Redman, L., Friman, M., Gärling, T., \& Hartig, T. (2013). Quality attributes of public transport that attract car users: A research review. Transport Policy, 25, 119-127. https://doi.org/10.1016/j.tranpol.2012.11.005.

17. Tyrinopoulos, Y., \& Antoniou, C. (2013). Factors affecting modal choice in urban mobility. Eur Transp Res Rev, 5, 27-39. https://doi.org/10.1007/s12544012-0088-3.

18. Varela, J. M. L., Börjesson, M., \& Daly, A. (2018). Public transport: One mode or several? Transportation Research Part A, 113, 137-156. https://doi.org/10.1 016/j.tra.2018.03.018

19. Ingvardson, J. B., \& Nielsen, O. A. (2018). Effects of new bus and rail rapid transit systems - an international review. Transport Reviews, 38(1), 96-116. https://doi.org/10.1080/01441647.2017.1301594.

20. Román, C., Martín, J. C., \& Espino, R. (2014). Using stated preferences to analyze the service quality of public transport. International Journal of Sustainable Transportation, 8(1), 28-46. https://doi.org/10.1080/15568318.2 012.758460

21. Börjesson, M., \& Eliasson, J. (2014). Experiences from the Swedish value of time study. Transp Res A Policy Pract, 59, 144-158. https://doi.org/10.1016/j. tra.2013.10.022.

22. van Lierop, D., \& El-Geneidy, A. M. (2018). Is having a positive image of public transit associated with travel satisfaction and continued transit usage? An exploratory study of bus transit. Public Transportation, 10(2), 241256. https://doi.org/10.1007/s12469-018-0175-5.

23. Rojo, M., Gonzalo-Orden, H., dell'Olio, L., Ibeas, Á., \& Ibeas, T. (2012). Relationship between service quality and demand for inter-urban buses. Transportation Research Part A: Policy and Practice, 46(10), 1716-1729. https:// doi.org/10.1016/j.tra.2012.07.006.

24. Eboli, L., \& Mazzulla, G. (2011). A methodology for evaluating transit service quality based on subjective and objective measures from the passenger's 
point of view. Transport Policy, 18(1), 172-181. https://doi.org/10.1016/j. tranpol.2010.07.007.

25. Friman, M., \& Fellesson, M. (2009). Service supply and customer satisfaction in public transportation: The quality paradox. Journal of Public Transportation, 12(4), 57-69. https://doi.org/10.5038/2375-0901.12.4.4.

26. Mouwen, A. (2015). Drivers of customer satisfaction with public transport services. Transportation Research Part A: Policy and Practice, 78, 1-20. https:// doi.org/10.1016/j.tra.2015.05.005.

27. White, P. (2016). Rural public transport. In Public transport: Its planning, management and operation (pp. 201-221). Oxford: Routledge.

28. CEN, European Committee for Standardisation. (2002). Transportation Logistics and services - Public passenger transport - Service quality definition, targeting and measurement (EN 13816:2002). Brussels: Author.

29. Taylor, B. D., Miller, D., Iseki, H., \& Fink, C. (2009). Nature and/or nurture? Analyzing the determinants of transit ridership across US urbanized areas. Transportation Research Part A: Policy and Practice, 43(1), 60-77. https://doi. org/10.1016/j.tra.2008.06.007.

30. Petersen, T. (2012). Public transport for exurban settlements (PhD thesis). Melbourne: The University of Melbourne.

31. Godlund, S. (1954). Verksamhets-, varaktighets- och miljöformerna inom billinjetrafiken. Tätortsavgränsingen. [Operational, durability and environmental forms within bus traffic. The urban area delimitation.]. In Busstrafikens framväxt och funktion i de urbana influensfälten [The growth and function of bus traffic in the urban influence fields] (pp. 27-42). Lund: C.W.K. Gleerup.

32. Luke, D., Steer, J., \& White, P. (2018). Interurban bus: Time to raise the profile. Greengauge, 21. http://www.greengauge21.net/wp-content/uploads/GG21_ IBR_A4P_WEB.pdf.

33. Hansson, J., Pettersson, F., Svensson, H., \& Wretstrand, A. (2018). Defining regional public transport (K2 working papers 2018:7). Lund: K2.

34. Moher, D., Liberati, A., Tetzlaff, J., Altman, D. G., \& The PRISMA Group. (2009). Preferred reporting items for systematic reviews and meta-analyses: The PRISMA statement. PLoS Medicine, 6(7). https://doi.org/10.1371/journal.pmed.1000097.

35. Transportation Research Board. (2018). Transportation Research Thesaurus, Retrieved March 20, 2018, from http://trt.trb.org/trt.asp?.

36. Hirsch, L., Thompson, K., \& Every, D. (2017). Frustrations, fights, and friendships: The physical, emotional, and behavioural effects of high-density crowding on Mumbai's suburban rail passengers. Qualitative Report, 22(2), 550-566 Retrieved from https://nsuworks.nova.edu/tar/vol22/iss2/12.

37. Rahman, S., \& Balijepalli, C. (2016). Understanding the determinants of demand for public transport: Evidence from suburban rail operations in five divisions of Indian Railways. Transport Policy, 48, 13-22. https://doi.org/10.1016/j.tranpol.2016.02.006.

38. Sahu, P. K., Sharma, G., \& Guharoy, A. (2018). Commuter travel cost estimation at different levels of crowding in suburban rail system: A case study of Mumbai. Transportation Research Board 97th Annual Meeting. https://trid.trb.org/view/1495556.

39. Zhou, X., Du, H., Liu, Y., Huang, H., \& Ran, B. (2017). Investigating the intention of rural residents to use transit in Cixi, China. Journal of Urban Planning and Development, 143(2). https://doi.org/10.1061/(ASCE)UP.1 943-5444.0000367.

40. Majumdar, S. R., \& Lentz, C. (2012). Individuals' attitudes toward public transit in a rural Transit District. Public Works Manag Policy, 17(1), 83-102. https://doi.org/10.1177/1087724X11421953.

41. Grisé, E., \& El-Geneidy, A. (2017). Where is the happy transit rider? Evaluating satisfaction with regional rail service using a spatial segmentation approach. Transportation Research Part A: Policy and Practice, 114(A), 84-96. https://doi. org/10.1016/j.tra.2017.11.005.

42. Bouscasse, H., Joly, I., \& Peyhardi, J. (2016). Estimating travel mode choice, including rail in regional area, based on a new family of regression models (GAEL Working Paper 2016-04). Retrieved from https://hal.archives-ouvertes. $\mathrm{fr} / \mathrm{hal}-01847227$.

43. Jiang, X., Guo, X., \& Ran, B. (2014). Optimization model for headway of a suburban bus route. Math Probl Mathematical Problems in Engineering, 2014. https://doi.org/10.1155/2014/979062.

44. Rashedi, Z., Mahmoud, M., Hasnine, S., \& Habib, K. N. (2017). On the factors affecting the choice of regional transit for commuting in Greater Toronto and Hamilton Area: Application of an advanced RP-SP choice model. Transportation Research Part A: Policy and Practice, 105, 1-13. https://doi. org/10.1016/j.tra.2017.08.008.

45. Asensio, J. (2000). The success story of Spanish suburban railways: Determinants of demand and policy implications. Transport Policy, 7(4), 295302. https://doi.org/10.1016/50967-070X(00)00030-5.
46. Berežný, R., \& Konecný, V. (2017). The impact of the quality of transport services on passenger demand in the suburban bus transport. Procedia Engineering, 192, 40-45. https://doi.org/10.1016/j.proeng.2017.06.007.

47. Garrido, C., De Oña, R., \& De Oña, J. (2014). Neural networks for analyzing service quality in public transportation. Expert Systems with Applications, 41(15), 6830-6838. https://doi.org/10.1016/j.eswa.2014.04.045.

48. Guirao, B., García-Pastor, A., \& López-Lambas, M. E. (2016). The importance of service quality attributes in public transportation: Narrowing the gap between scientific research and practitioners' needs. Transport Policy, 49, 68-77. https:// doi.org/10.1016/j.tranpol.2016.04.003.

49. Ramesh, A. V., Rao, K. R., \& Sarkar, A. K. (1998). The LOS index: An evaluation of regional bus services in Andhra Pradesh, India, using fuzzy set theory. Science, Technology and Development, 16(2), 112-123.

50. Rojo, M., Gonzalo-Orden, H., dell'Olio, L., \& Ibeas, A. (2011). Modelling gender perception of quality in interurban bus services. Proceedings of the Institution of Civil Engineers: Transport, 164(1), 43-53. https://doi.org/1 $0.1680 / \operatorname{tran} .9 .00031$

51. Stern, E. (1981). An innovative regional transit system in Israel. Urban Development and Urban Renewal, 125-132. https:/www.scopus.com/record/ display.uri?eid=2-s2.0-0019696952\&origin=inward\&txGid=10ee73d2069ba4 $715 f 8 f c b 4 c e c b 90270$.

52. Stark, D. C. (1981). Time series analysis of Glasgow suburban rail patronage (supplementary report 649). Crowthorne: U.K. Transport \& Road Research Laboratory.

53. Buehler, R., Pucher, J., \& Dümmler, O. (2018). Verkehrsverbund: The evolution and spread of fully integrated regional public transport in Germany, Austria, and Switzerland. International Journal of Sustainable Transportation. https:// doi.org/10.1080/15568318.2018.1431821.

54. Petersen, T. (2009). Network planning, Swiss style: Making public transport work in semi-rural areas. 32nd Australasian Transport Research Forum Retrieved from https://atrf.info/papers/2009/2009_petersen.pdf.

55. Petersen, T. (2016). Watching the Swiss: A network approach to rural and exurban public transport. Transport Policy, 52, 175-185. https://doi.org/10.1 016/j.tranpol.2016.07.012

56. White, P. (2016). The roles of 'conventional' and demand-responsive bus services. In C. Mulley \& J. D. Nelson (Eds.), Paratransit: Shaping the Flexible Transport Future (pp. 307-330). https://doi.org/10.1108/S2044994120160000008015.

57. Brown, J. R., \& Thompson, G. L. (2009). Express bus versus rail transit: How a marriage of mode and mission affects transit performance. Transportation Research Record, 2110(1), 45-54. https://doi.org/10.3141/2110-06.

58. Hasiak, S., Hasiak, F., \& Egea, A. (2016). Coach and train: Differences in individuals perception of these modes. Transportation Research Procedia, 14, 1706-1715. https://doi.org/10.1016/j.trpro.2016.05.136.

59. Jackson, J., Johnson, D., \& Nash, C. (2012). On the willingness to pay for rural rail service level changes. Res Transp Bus Manag, 4, 104-113. https://doi. org/10.1016/j.rtbm.2012.06.006.

60. Bazley, C., Vink, P., \& Blankenship, D. (2014). Survey results for rural bus rapid transit (BRT) VelociRFTA and future human factor considerations. Proceedings of the Human Factors and Ergonomics Society 58th Annual Meeting, 12241228. https://doi.org/10.1177/1541931214581255.

61. Akbari, S., Mahmoud, M. S., Shalaby, A., \& Habib, K. M. (2018). Empirical models of transit demand with walk access/egress for planning transit oriented developments around commuter rail stations in the greater Toronto and Hamilton area. Journal of Transport Geography, 68, 1-8. https:// doi.org/10.1016/j.jtrangeo.2018.02.002.

62. Brand, J., Hoogendoorn, S., Van Oort, N., \& Schalkwijk, B. (2017). Modelling multimodal transit networks integration of bus networks with walking and cycling. In 2017 5th IEEE international conference on models and Technologies for Intelligent Transportation Systems (MT-ITS) (pp. 750-755). https://doi.org/1 0.1109/MTITS.2017.8005612.

63. Ker, I., \& Ginn, S. (2003). Myths and realities in walkable catchments: The case of walking and transit. Road and Transport Research, 12(2), 69-80.

64. Vijayakumar, N., El-Geneidy, A. M., \& Patterson, Z. (2011). Driving to suburban rail stations: Understanding variables that affect driving distance and station demand. Transportation Research Record, 2219, 97-103. https://doi.org/1 $0.3141 / 2219-12$.

65. Hamer, P. (2010). Analysing the effectiveness of park and ride as a generator of public transport mode shift. Road and Transport Research, 19(1), 51-107.

66. Hanssen, J. U., Tennøy, A., Christiansen, P., \& Øksenholt, K. V. (2016). How can $P \& R$ facilities contribute to reduced emissions of greenhouse gases? 
European Transport Conference Retrieved from https://aetransport.org/ public/downloads/ljecn/4819-57e51951a4f4c.pdf.

67. Niles, J., \& Pogodzinski, J. M. (2016). Bus Transit Operational Efficiency Resulting from Passenger Boardings at Park-and-Ride Facilities (MTI report 1260). San José, CA: Mineta Transportation Institute Retrieved from http:// transweb.sjsu.edu/PDFs/research/1401-park-and-ride-bus-passengerboarding-efficiency.pdf.

68. Monsuur, F., Enoch, M., Quddus, M., \& Meek, S. (2017). The impact of train and station types on perceived rail service quality. Transportation Research Record, 2648, 51-59. https://doi.org/10.3141/2648-06.

69. Kroes, E., Kouwenhoven, M., Duchateau, H., Debrincat, L., \& Goldberg, J. (2007). Value of punctuality on suburban trains to and from Paris. Transportation Research Record, 2006, 67-75. https://doi.org/10.3141/2006-08,

70. Mahmoud, M. S., Shalaby, A., Habib, K. N., \& Shalaby, A. (2016). Application of RP/SP data to the joint estimation of mode choice models: Lessons learned from an empirical investigation into cross-regional commuting trips in the greater Toronto and Hamilton area. Transportation Research Board 95th Annual Meeting Retrieved from https://trid.trb.org/view/1393247.

\section{Publisher's Note}

Springer Nature remains neutral with regard to jurisdictional claims in published maps and institutional affiliations.

\section{Submit your manuscript to a SpringerOpen ${ }^{\circ}$ journal and benefit from:}

- Convenient online submission

- Rigorous peer review

- Open access: articles freely available online

- High visibility within the field

- Retaining the copyright to your article

Submit your next manuscript at $\boldsymbol{\wedge}$ springeropen.com 